Tropical Journal of Pharmaceutical Research April 2017; 16 (4): 819-825

ISSN: $1596-5996$ (print); 1596-9827 (electronic)

(C) Pharmacotherapy Group, Faculty of Pharmacy, University of Benin, Benin City, 300001 Nigeria.

All rights reserved.

Available online at http://www.tjpr.org

Original Research Article

http://dx.doi.org/10.4314/tjpr.v16i4.11

\title{
Rice bran water extract attenuates pancreatic abnormalities in high-fat diet-induced obese rats
}

\author{
Wason Parklak ${ }^{1 \star}$, Narongsuk Munkong ${ }^{2}$, Surasawadee Somnuk ${ }^{1}$, Nuntiya \\ Somparn ${ }^{3}$, Jarinyaporn Naowaboot ${ }^{3}$, Bhornprom Yoysungnoen ${ }^{3}$ and Nusiri \\ Lerdvuthisopon ${ }^{3}$ \\ ${ }^{1}$ Office of Graduate Studies, Faculty of Medicine, Thammasat University, Pathum Thani 12120, ${ }^{2}$ Department of Medicine, \\ School of Medicine, University of Phayao, Phayao 56000, ${ }^{3}$ Department of Preclinical Science, Faculty of Medicine, Thammasat \\ University, Pathum Thani 12120, Thailand
}

*For correspondence: Email: toon.wason@gmail.com; Tel: +669 4249 3687; Fax: +66 29269755

Received: 17 November 2016

Revised accepted: 6 February 2017

\begin{abstract}
Purpose: To investigate the protective potential of rice bran water extract (RBE) from Khao Dawk Mali 105 on pancreatic abnormalities in high-fat diet (HFD)-induced obese rats.

Methods: Male Sprague-Dawley rats were divided into 4 groups: control group, HFD group, and HFD group treated with RBE at 2,205 or 4,410 mg/kg/day. After 4 weeks, body weight, glucose homeostatic parameters, and pancreatic fat accumulation were assessed. IRNA expression levels of sterol regulatory element-binding protein-1c (SREBP-1c), insulin receptor substrate-2 (IRS-2), glucose transporter-2 (GLUT-2) and glucokinase (GK) genes in pancreas were also analyzed.

Results: Compared with HFD group, two doses of RBE-treated rats significantly $(p<0.05)$ reversed HFD-induced obesity, hyperglycemia, impaired glucose tolerance and pancreatic triglyceride accumulation in rats. Histological examination of HFD-induced obese rats revealed fat droplets in acinar cells, but these alterations were ameliorated in RBE-treated rats. RBE treatment showed significantly ( $p$ $<0.05)$ decreased SREBP-1c expression, and also significantly $(p<0.05)$ increased IRS-2, GLUT-2 and $G K$ expressions in pancreas.

Conclusion: RBE consumption may attenuate pancreatic abnormalities by inhibiting fat accumulation, as well as enhancing insulin sensitivity and glucose sensing in the pancreas of HFD-induced obese rats.
\end{abstract}

Keywords: Rice bran, Obesity, Pancreatic steatosis, Insulin signaling, Glucose sensor

Tropical Journal of Pharmaceutical Research is indexed by Science Citation Index (SciSearch), Scopus, International Pharmaceutical Abstract, Chemical Abstracts, Embase, Index Copernicus, EBSCO, African Index Medicus, JournalSeek, Journal Citation Reports/Science Edition, Directory of Open Access Journals (DOAJ), African Journal Online, Bioline International, Open-J-Gate and Pharmacy Abstracts

\section{INTRODUCTION}

Obesity, especially abdominal obesity, appears to play an important role in the impairment of glucose and lipid metabolism, such as hyperglycemia, insulin resistance, ectopic fat deposition and dyslipidemia $[1,2]$. Consumption of high-energy diets with increased saturated and/or trans-fats, an important environmental cause of obesity, are also associated with the initiation of these metabolic disturbances [2].
Under physiological conditions, the pancreas is an important organ for the regulation of cellular and whole-body energy homeostasis. Pancreatic abnormalities linked to the development of obesity, insulin resistance and type 2 diabetes (T2D) $[3,4]$. Pancreatic steatosis can occur in the presence of obesity [5]. Sterol regulatory element-binding protein-1c (SREBP-1c) is now well established as a key transcription factor in the regulation of lipogenesis in the pancreas [6]. A previous report has indicated that activation of 
SREBP-1C is essential for impaired insulin secretion and islet mass associated with the accumulation of triglycerides (TG) [7].

Insulin signals are mediated by tyrosine phosphorylation of the insulin receptor and its downstream targets, such as insulin receptor substrate-2 (IRS-2). IRS-2 acts as important coordinator of insulin signaling. It plays a major role in maintaining pancreatic structure and function by regulating insulin secretion and pancreatic cell mass [8]. Down-regulation of IRS2 gene in the $\beta$-cells led to impaired glucosestimulated insulin secretion (GSIS) [8,9]. In addition, impaired glucose sensing of the pancreatic $\beta$-cell resulted in the decrease of insulin secretion, thus promoting of glucose intolerance in a human study [10]. This impairment is believed to be initiated after the down-regulation of glucose transporter-2 (GLUT2) and glucokinase (GK) gene, which are important glucose-sensing genes [11].

There are many reports on anti-obesity [12], antidyslipidemic [13], and antioxidant [13] effects of rice bran extract. According to previous research [14], consumption of rice bran water extract (RBE) may reduce hyperglycemia and hyperlipidemia in humans with diabetes mellitus. Consumption of RBE (at least 2,205 mg $/ \mathrm{kg}$ ) also reduced abdominal fat weight, hyperglycemia and hyperlipidemia in HFD-fed rats [15]. These studies indicate a role for RBE in the regulation of glucose and lipid, but the mechanisms that regulate fat accumulation and insulin signaling in pancreas remains unknown. Therefore, the aim of this study was to investigate the protective effect of RBE on pancreatic abnormalities in HFD-induced obese rats.

\section{EXPERIMENTAL}

\section{Chemicals}

Rat insulin ELISA kit was purchased from Mercodia Co. (Sweden). Fluitest lipid assay kit was purchased from Analyticon Biotechnologies $A G$ Co. (Germany). Trizol reagent was purchased from Invitrogen Co. (USA), cDNA synthesis and real-time polymerase chain reaction (PCR) kit were purchased from Applied Biosystems Co. (USA). All other reagents used were of analytic grade.

\section{RBE Preparation}

Rice bran of Khao Dawk Mali 105 was purchased from the Rice Fund Surin Organic Agriculture Corporative, Ltd. (Surin Province, Thailand). For extraction, about $2 \mathrm{~kg}$ sample of stabilized rice bran was mixed with $8 \mathrm{~L}$ of distilled water and boiled at $70^{\circ} \mathrm{C}$ for $60 \mathrm{~min}$. Then, the extract was centrifuged at $8,000 \mathrm{rpm}$ at $25^{\circ} \mathrm{C}$ for $10 \mathrm{~min}$ to recover the supernatant fraction containing the water-soluble extract, designated RBE. The RBE solution was lyophilized and then stored at -40 ${ }^{\circ} \mathrm{C}$ until use. The process of preparation has been described in details by Qureshi et al [14]. For animal treatment, RBE was dissolved in distilled water.

\section{Animals}

Male Sprague-Dawley rats (weight $180-220 \mathrm{~g}$ ) were obtained from the National Laboratory Animal Center of Mahidol University, Thailand and allowed to acclimate to the animal facility for 1 week before being fed experimental diets. All of the rats were housed at $24 \pm 1{ }^{\circ} \mathrm{C}$ with a 12 -h light-dark cycle. The animal care and use was performed according to guidelines of National Research Council (NRC) [16]. The ethical approval for conducting animal study was obtained from the Animal Ethics Committee of Thammasat University, Pathum Thani, Thailand (approval ref no. AE 002/2013).

\section{Experimental design}

Four groups of 6 rats were established as follows: Group 1 (C) was maintained on a standard chow (13\% energy as fat) based on a commercial diet (No. 082G, Charoen Pokphand Foods, Thailand); Group 2 (HF) was fed with HFD (65\% energy as fat) and it was prepared as previously described [17] with minor modifications; Group 3 (HFR1) was fed with HFD and RBE 2,205 mg/kg/day; and Group 4 (HFR2) was fed with HFD and RBE $4,410 \mathrm{mg} / \mathrm{kg} /$ day. RBE was suspended in distilled water. RBEtreated rats were orally administered daily using a feeding needle. All of the rats were allowed free access to food and water. Food intake was measured daily, and the rats were weighed daily. After 4 weeks of treatment, the rats were euthanized with an overdose of pentobarbital sodium (intraperitoneal injection), and the pancreas tissues were rapidly excised for biochemical analyses and histological examinations.

\section{Determination of glucose tolerance, fasting blood glucose (FBG), and serum insulin levels}

At the end of treatment, rats of each group were orally gavaged with glucose at $2.0 \mathrm{~g} / \mathrm{kg}$ for oral glucose tolerant test (OGTT), after an overnight fast. Blood samples were collected from the tail vein at 0 (FBG), 30, 60, 90, 120, and $150 \mathrm{~min}$. 
Blood glucose levels were measured by a glucometer (Roche, Switzerland). The area under the curve of blood glucose levels (AUC-G), which indicated the total amount of blood glucose from 0 to $150 \mathrm{~min}$, was determined. Insulin levels were measured by enzyme-linked immunosorbent assay (ELISA) kit.

\section{Measurement of pancreatic TG accumulation}

Pancreatic TG content was extracted from fresh pancreas $(50 \mathrm{mg})$ using isopropanol according to Oakes et al [18]. The concentration of TG was measured using Fluitest lipid assay kits and expressed as $\mathrm{mg} / \mathrm{g}$ tissue.

\section{Real-time PCR analysis}

Total pancreatic RNA was extracted by the TRIzol isolation method according to the manufacturer's protocol (Invitrogen, USA). For quantitative real-time PCR, the first strand CDNA was synthesized from $200 \mathrm{ng}$ of total RNA using high capacity cDNA reverse transcription kits. Samples were subjected to quantitative amplification using TaqMan probe and primer sets for rat SREBP-1c (Rn01495769 m1), IRS-2 (Rn01482270_s1), GLUT-2 (Rn00563565_m1) and GK (Rn00561265_m1). The relative mRNA levels were analyzed by $2^{-\Delta \Delta C T}$ method. Expressions of target gene were normalized with $\beta$-actin gene (Rn00667869_m1) expression as a housekeeping gene.

\section{Histological examination}

Briefly, the rat pancreatic tissues were fixed with $10 \%$ formalin, embedded in paraffin, sectioned and stained with hematoxylin and eosin $\mathrm{H}$ and E). The stained sections were examined for morphology under a light microscope (Eclipse Ci$L$ microscope, Nikon, Japan) equipped with a digital camera (DS-Fi2 microscope camera, Nikon). Mean area of islets were calculated in ten islets per pancreatic section for each rat $(n=$ $3 /$ group). Area of the islets was measured by
Axiovision AC microscopy software (Carl Zeiss, Germany).

\section{Statistical analysis}

Data are presented as mean \pm standard error of the mean (SEM). Statistical analysis was performed using the SPSS program (version 16.0). Data were analyzed by one-way analysis of variance (ANOVA). Differences between groups were established using least significant difference (LSD) test and significance level was set at $p<0.05$.

\section{RESULTS}

\section{Effect of RBE on dietary intake and body weight}

As shown in Table 1, C group consumed significantly $(p<0.05)$ more food than HF group per day. However, the energy intake was significantly $(p<0.05)$ higher in HF, HFR1 and HFR2 groups than in $C$ group. Food and energy intakes were not significantly $(p<0.05)$ different among HFD-fed rats. The initial body weight of rats before treatment did not significantly $(p<$ 0.05 ) differs among the experimental groups. After 4 weeks, the final body weight and body weight gain of rats were significantly $(p<0.05)$ increased in the HF group compared with the $\mathrm{C}$ group. However, these elevations were significantly $(p<0.05)$ decreased after rats were treated with the RBE.

\section{Effect of RBE on glucose homeostatic parameters}

Table 2 shows the effect of RBE on glucose homeostatic parameters. The HF group exhibited significantly $(p<0.05)$ higher levels of FBG, serum insulin and AUC-G than $C$ group. Interestingly, treatment with RBE in HFR1 and HFR2 groups significantly $(p<0.05)$ decreased both FBG and serum insulin levels as compared with the HF group.

Table 1: Effect of RBE on dietary intake and body weight in HFD-induced obese rats

\begin{tabular}{lcccc}
\hline Parameter & C & HF & HFR1 & HFR2 \\
\hline Dietary intake & & & & \\
Food (g/day) & $23.21 \pm 0.05^{\mathrm{a}}$ & $19.07 \pm 0.33^{\mathrm{b}}$ & $18.59 \pm 0.55^{\mathrm{b}}$ & $18.23 \pm 0.54^{\mathrm{b}}$ \\
Energy (kcal/day) & $70.56 \pm 0.16^{\mathrm{b}}$ & $97.66 \pm 1.69^{\mathrm{a}}$ & $95.21 \pm 2.8^{\mathrm{a}}$ & $94.84 \pm 2.06^{\mathrm{a}}$ \\
Body weight & & & & \\
Initial (g) & $244.30 \pm 2.08^{\mathrm{a}}$ & $243.69 \pm 1.80^{\mathrm{a}}$ & $244.06 \pm 1.20^{\mathrm{a}}$ & $241.34 \pm 1.80^{\mathrm{a}}$ \\
Final (g) & $366.05 \pm 0.93^{\mathrm{b}}$ & $413.24 \pm 2.28^{\mathrm{a}}$ & $367.20 \pm 6.85^{\mathrm{b}}$ & $358.78 \pm 7.35^{\mathrm{b}}$ \\
Gain (g) & $123.55 \pm 1.13^{\mathrm{b}}$ & $168.52 \pm 1.86^{\mathrm{a}}$ & $121.45 \pm 3.98^{\mathrm{b}}$ & $117.58 \pm 7.72^{\mathrm{b}}$ \\
\hline
\end{tabular}

Values are presented as means \pm SEM $(n=6)$. Mean values with unlike letters along the same row each parameters are significantly different $(p<0.05)$. C: control; HF: HFD alone; HFR1: HFD + RBE 2,205 mg/kg; HFR2: HFD + RBE 4,410 mg/kg 
AUC-G showed a tendency to be reduced in the HFR2 group compared with the HF group, but the difference was not significant. However, HFR1 group exhibited significantly $(p<0.05)$ lower AUC-G than HF group.

\section{Effect of RBE on histology of pancreatic tissue}

When compared to the $\mathrm{C}$ group, the area of islet was significantly $(p<0.05)$ higher in the HF group $\left(17976.0 \pm 1543.0 \mu \mathrm{m}^{2}\right)$. The HFR1 and HFR2 groups exhibited significantly $(p<0.05)$ lower islet area than the HFD alone group $\left(10170.1 \pm 626.7\right.$ and $11847.0 \pm 2898.8 \mu \mathrm{m}^{2}$, respectively). Examination of $\mathrm{H}$ and E-stained sections of the pancreatic islets and acinar cells in the $C$ group revealed no obvious changes (Figure $1 \mathrm{~A}$ and $1 \mathrm{~B}$, respectively). Irregular and larger shapes of islets were observed after the rats were fed with HFD for 4 weeks. In addition, vacuoles were obvious in acinar cells of obese rats. The islets of HFR1 and HFR2 groups that received RBE showed smaller shape than those in the HF group. Moreover, acinar cells of the RBE-treated rats displayed decreased vacuoles compared to the HF group.

\section{Effect of RBE on fat accumulation in pancreatic tissue}

As presented in Figure 2, HF group exhibited significantly $(p<0.05)$ increased both pancreatic TG and SREBP-1c mRNA levels as compared with $C$ group. However, the pancreatic $T G$ and SREBP-1c mRNA levels were significantly $(p<$ 0.05 ) decreased in RBE-treated rats compared with the rats fed an HFD alone.

\section{Effect of RBE on pancreatic insulin signaling and glucose-sensing pathways}

Compared with the $\mathrm{C}$ group, the mRNA levels of IRS-2, GLUT-2 and GK were significantly $(p<$ $0.05)$ decreased in the HFD alone feed group (Figure 5A, 5B and 5C, respectively). In contrast to the HF group, GLUT-2 and IRS-2 mRNA levels were significantly $(p<0.05)$ increased in the HFR1 and HFR2 groups compared with the HF group. GK mRNA levels were also significantly $(p<0.05)$ increased in the HFR1 group. HFR2 group also showed a tendency towards increased GK expression, but the difference was not significant.

Table 2: Effect of RBE on glucose homeostatic parameters in HFD-induced obese rats

\begin{tabular}{lcccc}
\hline Parameter & C & HF & HFR1 & HFR2 \\
\hline FBG $(\mathrm{mg} / \mathrm{dL})$ & $105.00 \pm 1.53^{\mathrm{b}}$ & $116.17 \pm 1.05^{\mathrm{a}}$ & $105.67 \pm 1.45^{\mathrm{b}}$ & $107.33 \pm 2.30^{\mathrm{b}}$ \\
Insulin $(\mathrm{mU} / \mathrm{L})$ & $35.46 \pm 2.86^{\mathrm{b}}$ & $45.06 \pm 1.93^{\mathrm{a}}$ & $32.21 \pm 1.32^{\mathrm{b}}$ & $33.10 \pm 3.50^{\mathrm{b}}$ \\
AUC-G & $2530.29 \pm 110.88^{\mathrm{c}}$ & $4025.00 \pm 244.85^{\mathrm{a}}$ & $2922.74 \pm 339.02^{\mathrm{b}, \mathrm{c}}$ & $3379.03 \pm 226.76^{\mathrm{a}, \mathrm{b}}$ \\
(mg/dL·min) & & & \\
\hline Values are presented as means \pm SEM $(\mathrm{n}=6)$. & Mean values with unlike letters along the same row each \\
parameters are significantly different $(p<0.05)$. C: control; HF: HFD alone; HFR1: HFD + RBE 2,205 mg/kg; \\
HFR2: HFD + RBE 4,410 mg/kg
\end{tabular}
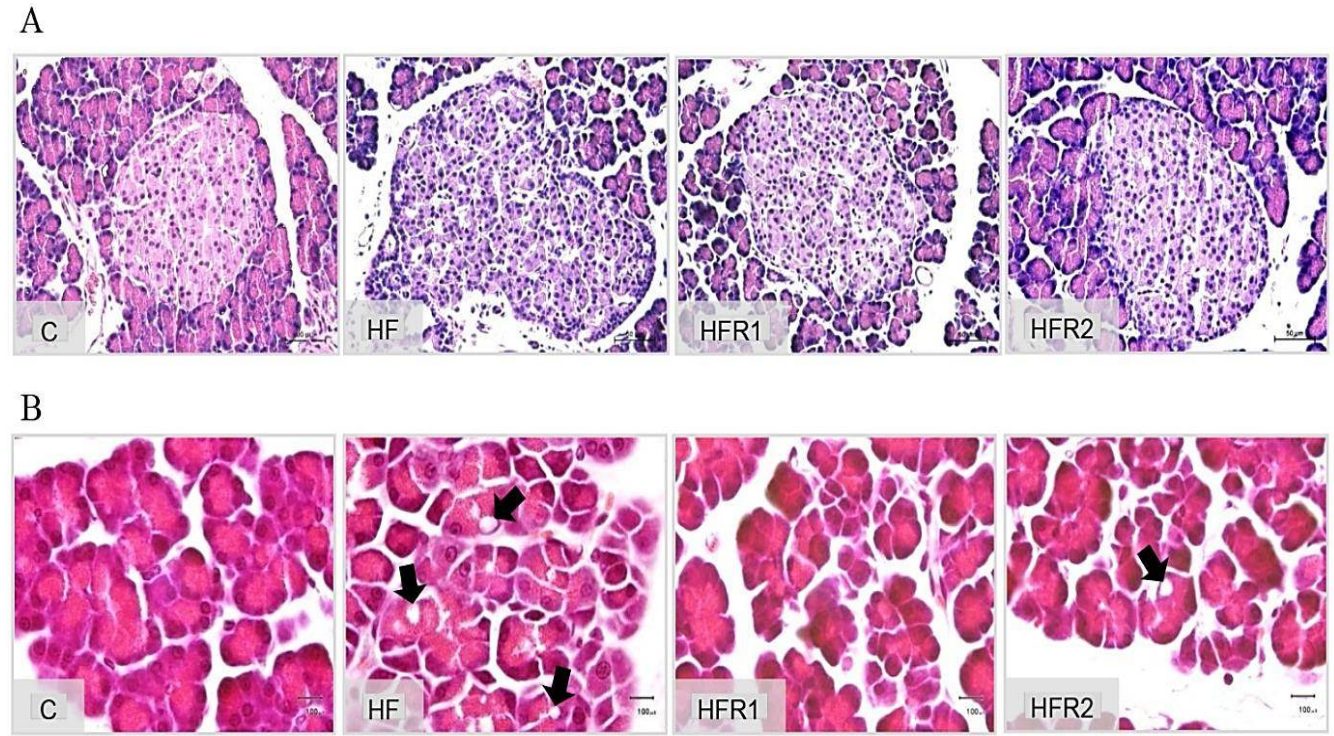

Figure 1: Effect of RBE on histology $(H$ and $E$ staining) of pancreatic islets (400x magnification; scale bar $=50$ $\mu \mathrm{m})(\mathrm{A})$ and acinar cells $(1,000 \times$ magnification; scale bar $=100 \mu \mathrm{m})(\mathrm{B})$ in HFD-induced obese rats. Arrows represent clear vacuoles in pancreatic acinar cells. C: control; HF: HFD alone; HFR1: HFD + RBE 2,205 mg/kg; HFR2: HFD + RBE 4,410 mg/kg 
A

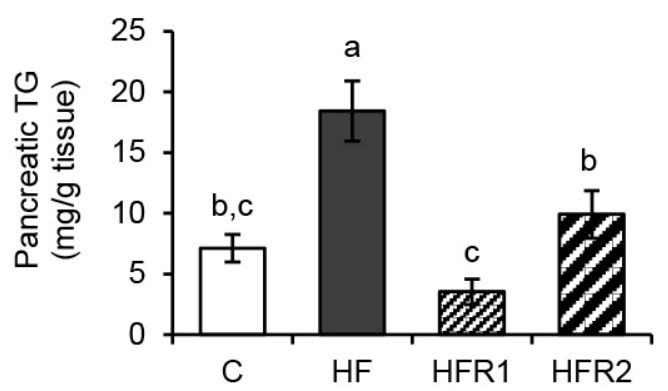

$\mathrm{B}$

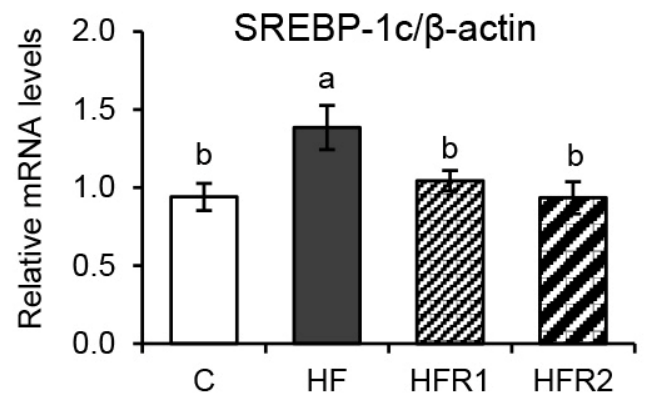

Figure 2: Effect of RBE on pancreatic TG $(A)$ and SREBP-1c mRNA expression (B) in the pancreas of HFDinduced obese rats. Data are means $\pm \operatorname{SEM}(n=6)$. Mean values with unlike letters are significantly different $(p<$ 0.05). C: control; HF: HFD alone; HFR1: HFD + RBE 2,205 mg/kg; HFR2: HFD + RBE 4,410 mg/kg

A

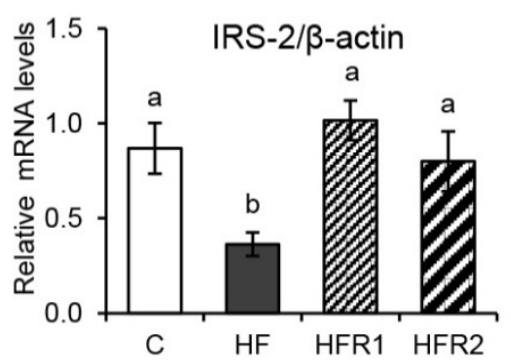

B

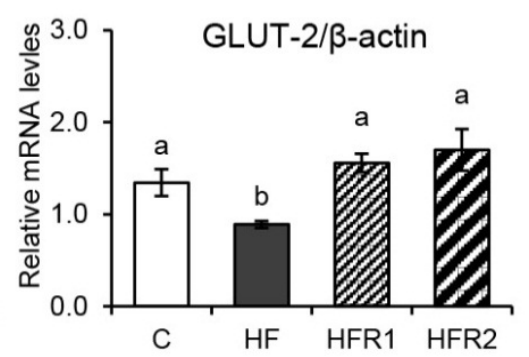

$\mathrm{C}$

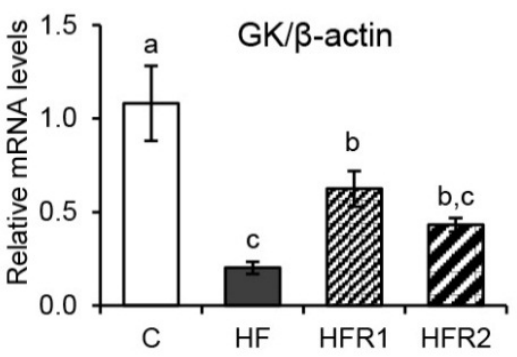

Figure 3: Effects of RBE on mRNA expression levels of IRS-2 (A), GLUT-2 (B) and GK (C) in the pancreas of HFD-induced obese rats. Data are means \pm SEM $(n=6)$. Mean values with unlike letters are significantly different $(p<0.05)$. C: control; HF: HFD alone; HFR1: HFD + RBE 2,205 mg/kg; HFR2: HFD + RBE 4,410 mg/kg

\section{DISCUSSION}

Impaired glucose and lipid metabolism, such as hyperglycemia, insulin resistance, ectopic fat deposition, and dyslipidemia, are the common pathological features of obesity and are associated with pancreatic abnormalities [1,4]. HFD was used in the present study to mimic human diets that have been linked to the development of metabolic syndrome [2]. After 4 weeks of feeding, HFD consumption produced changes in metabolic parameters including elevated body weight associated with excessive abdominal fat deposition (data not shown), hyperglycemia, hyperinsulinemia and impaired glucose tolerance. In the present study, the administration of RBE caused a significant reduction in these metabolic changes in rats fed with HFD. Thus, our results imply that RBE treatment may lead to amelioration of HFDinduced obesity and metabolic disturbances. These results further support the anti-obesity and hypoglycemic properties of $R B E$ previously reported in animal models of metabolic syndrome $[12,15]$. Moreover, rice bran protein and phytic acid, the important bioactive compounds in rice bran, have also been shown to exert significant hypoglycemic effects in high-calorie-fed animals $[19,20]$.
We also evaluated the effect of RBE on HFDinduced ectopic fat deposition in the pancreas. Excessive lipid accumulation in the pancreas can promote insulin resistance, oxidative stress and apoptosis in tissues [21]. SREBP-1c has been proposed as a major lipogenic transcription factor in various tissues including the pancreas [6]. Activation of SREBP-1c in response to various metabolic stimuli, including hyperinsulinemia, hyperglycemia and high FFA levels, results in the up-regulation of lipogenic genes [7,22]. The upregulation of this transcription factor in the pancreas was found in association with the accumulation of TG $[6,23]$. In the present study, histological examination of pancreatic acinar cells in HFD-induced obese rats revealed marked accumulation of fat droplets, indicating ectopic fat deposition in the pancreas. Similar results were found in animal models of metabolic syndrome $[24,25]$. In parallel, HFD-fed rats also showed a marked increase in TG levels in the pancreas along with up-regulated SREBP-1C expression. However, treatment with RBE markedly lowered pancreatic fat deposition and SREBP-1c mRNA levels in rats fed an HFD. Our results indicate that the RBE treatment may prevent ectopic fat deposition in the pancreas, at least in part, via a decrease in SREBP-1C expression. The inhibitory effect of RBE on 
SREBP-1c may be mediated, at least in part, by the reduction of serum insulin and glucose levels.

IRS-2 plays an important role in regulating pancreatic mass, insulin synthesis and glucose sensing. Under HFD conditions, down-regulation of IRS-2 was observed in the pancreas in association with impairment of pancreatic mass and function [26]. In addition to the abnormal insulin signaling, down-regulations of GLUT-2 and $\mathrm{GK}$ genes were observed in the pancreas induced by HFD, thus reducing glucose sensing [11]. The down-regulation of IRS-2, GLUT-2 and GK genes may, therefore, lead to hyperglycemia and glucose intolerance [8,11]. In agreement with previous reports, we found that after HFD feeding, pancreatic IRS-2, GLUT-2 and GK mRNA levels were decreased, thus, suggesting that HFD might interfere with insulin signaling and glucose-sensing pathways in the pancreas. However, the current results showed that RBE treatments were able to up-regulate IRS-2, GLUT-2 and GK gene in the pancreases of HFDfed rats. Thus, our findings suggest that RBE treatments might prevent impairment of insulin signaling and glucose-sensing pathways in the pancreas.

\section{CONCLUSION}

RBE consumption can attenuate abnormalities in the pancreas by reducing fat deposition as well as improving insulin signaling and glucose sensing. These protective effects may be via the inhibition of lipogenic gene (SREBP-1c) expression and activation of insulin signaling and glucose-sensing gene (IRS-2, GLUT-2 and GK) expression. Thus, the protective effect of RBE may be attributed to improved glucose homeostasis in HFD-induced obesity condition. Hence, RBE may be useful as an alternative nutritional complement in combination with other preventive and therapeutic strategies against pancreatic abnormalities associated with obesity.

\section{DECLARATIONS}

\section{Acknowledgement}

This work was supported by grants from the Research Unit, Faculty of Medicine, Thammasat University, National Research Council of Thailand and the Higher Education Research Promotion and National Research University Project of Thailand (grant nos. 2-17/2013, 201167 and 14/2015, respectively).

\section{Conflict of Interest}

No conflict of interest associated with this work.

\section{Contribution of Authors}

The authors declare that this work was done by the authors named in this article and all liabilities pertaining to claims relating to the content of this article will be borne by them.

\section{Open Access}

This is an Open Access article that uses a funding model which does not charge readers or their institutions for access and distributed under the terms of the Creative Commons Attribution License (http://creativecommons.org/licenses/by/ 4.0) and the Budapest Open Access Initiative (http://www.budapestopenaccessinitiative.org/rea d), which permit unrestricted use, distribution, and reproduction in any medium, provided the original work is properly credited.

\section{REFERENCES}

1. Singla $P$, Bardoloi A, Parkash AA. Metabolic effects of obesity: A review. World J Diabetes 2010; 1(3): 76-88.

2. Buettner R, Schölmerich J, Bollheimer LC. High-fat diets: modeling the metabolic disorders of human obesity in rodents. Obesity 2007; 15(4): 798-808.

3. Aronoff SL, Berkowitz K, Shreiner B, Want L. Glucose metabolism and regulation: beyond insulin and glucagon. Diabetes Spectrum 2004; 17(3): 184-190.

4. Panchal SK, Poudyal H, lyer A, Nazer R, Alam A, Diwan $V$, Kauter K, Sernia C, Campbell F, Ward L, et al. Highcarbohydrate high-fat diet-induced metabolic syndrome and cardiovascular remodeling in rats. J Cardiovasc Pharmacol 2011; 57(1): 51-64.

5. Pezzilli R, Calculli L. Pancreatic steatosis: Is it related to either obesity or diabetes mellitus? World J Diabetes 2014; 5(4): 415-419.

6. Shao S, Yang Y, Yuan G, Zhang M, Yu X. Signaling molecules involved in lipid-induced pancreatic beta-cell dysfunction. DNA Cell Biol 2013; 32(2): 41-49.

7. Takahashi A, Motomura $K$, Kato $T$, Yoshikawa $T$, Nakagawa $Y$, Yahagi $N$, Sone $H$, Suzuki $H$, Toyoshima $H$, Yamada $N$, et al. Transgenic mice overexpressing nuclear SREBP-1C in pancreatic beta-cells. Diabetes 2005; 54(2):492-499.

8. Assmann A, Ueki K, Winnay JN, Kadowaki T, Kulkarni $R N$. Glucose effects on beta-cell growth and survival require activation of insulin receptors and insulin receptor substrate 2. Mol Cell Biol 2009; 29(11): 32193228.

9. Hashimoto S, Kubota N, Sato H, Sasaki M, Takamoto I, Kubota $T$, Nakaya K, Noda M, Ueki K, Kadowaki $T$. Insulin receptor substrate-2 (Irs2) in endothelial cells 
plays a crucial role in insulin secretion. Diabetes 2015; 64(3): 876-886.

10. Ahrén B. Beta- and alpha-cell dysfunction in subjects developing impaired glucose tolerance: outcome of a 12-year prospective study in postmenopausal caucasian women. Diabetes 2009; 58(3): 726-731.

11. Cerf ME. High fat diet modulation of glucose sensing in the beta-cell. Med Sci Monit 2007; 13(1): RA12-17.

12. Candiracci $M$, Justo $M L$, Castaño $A$, RodriguezRodriguez $R$, Herrera $M D$. Rice bran enzymatic extractsupplemented diets modulate adipose tissue inflammation markers in Zucker rats. Nutrition 2014; 30(4): 466-472.

13. Wang YX, Li Y, Sun AM, Wang FJ, Yu GP. Hypolipidemic and antioxidative effects of aqueous enzymatic extract from rice bran in rats fed a high-fat and-cholesterol diet. Nutrients 2014; 6(9): 3696-3710.

14. Qureshi AA, Sami SA, Khan FA. Effects of stabilized rice bran, its soluble and fiber fractions on blood glucose levels and serum lipid parameters in humans with diabetes mellitus Types I and II. J NutrBiochem 2002; 13(3): 175-187.

15. Munkong N, Hansakul $P$, Yoysungnoen $B$, Wongnoppavich $A$, Sireeratawong $S$, Kaendee $N$, Lerdvuthisopon $N$. Vasoprotective effects of rice bran water extract on rats fed with high-fat diet. Asian Pac J Trop Biomed 2016; 6(9): 778-784.

16. National Research Council (NRC). Guide for the Care and Use of Laboratory Animals: 8th Ed, 2011. [cited 2013 Apr 3]. Available from: https://grants.nih.gov/grants/olaw/Guide-for-the-Careand-use-of-laboratory-animals.pdf.

17. Claret M, Corominola H, Canals I, Nadal B, Chavanieu A, Pfeiffer $B$, Renard $P$, Gorostiaga $C$, Delagrange $P$, Grassy $G$, et al. $S 23521$ decreases food intake and body weight gain in diet-induced obese rats. Obes Res 2004; 12(10):1596-1603.

18. Oakes ND, Thalén PG, Jacinto SM, Ljung $B$. Thiazolidinediones increase plasma-adipose tissue FFA exchange capacity and enhance insulin-mediated control of systemic FFA availability. Diabetes 2001; 50(5):1158-1165.

19. Boonloh K, Kukongviriyapan V, Kongyingyoes $B$, Kukongviriyapan U, Thawornchinsombut S, Pannangpetch $P$. Rice bran protein hydrolysates improve insulin resistance and decrease proinflammatory cytokine gene expression in rats fed a high carbohydrate-high fat diet. Nutrients 2015; 7(8): 63136329.

20. Kim SM, Rico CW, Lee SC, Kang MY. Modulatory effect of rice bran and phytic acid on glucose metabolism in high fat-fed C57BL/6N Mice. J ClinBiochemNutr 2010; 47(1): 12-17.

21. van Raalte $D H$, van der Zijl NJ, Diamant M. Pancreatic steatosis in humans: cause or marker of lipotoxicity? Curr Opin Clin Nutr Metab Care 2010; 13(4): 478-485.

22. Gosmain Y, Dif N, Berbe V, Loizon E, Rieusset J, Vidal $H$, Lefai $E$. Regulation of SREBP-1 expression and transcriptional action on HKII and FAS genes during fasting and refeeding in rat tissues. J Lipid Res 2005; 46(4): 697-705.

23. Shimano H, Amemiya-Kudo M, Takahashi A, Kato $T$, Ishikawa $M$, Yamada $N$. Sterol regulatory elementbinding protein-1C and pancreatic beta-cell dysfunction. Diabetes Obes Metab 2007; 9 Suppl 2:133-139.

24. Lee Y, Lingvay I, Szczepaniak LS, Ravazzola M, Orci L, Unger RH. Pancreatic steatosis: harbinger of type 2 diabetes in obese rodents. Int $J$ Obes 2010; 34: 396400.

25. Matsuda A, Makino N, Tozawa T, Shirahata N, Honda $T$, Ikeda $Y$, Sato $H$, Ito $M$, Kakizaki $Y$, Akamatsu $M$, et al. Pancreatic fat accumulation, fibrosis, and acinar cell injury in the zucker diabetic fatty rat fed a chronic highfat diet. Pancreas 2014; 43(5): 735-743.

26. Park S, Hong SM, Lee JE, Sung SR. Exercise improves glucose homeostasis that has been impaired by a highfat diet by potentiating pancreatic beta-cell function and mass through IRS2 in diabetic rats. J Appl Physiol 2007; 103(5): 1764-1771. 